\title{
Activation of Toll Pathway Is Different between Kuruma Shrimp and Drosophila
}

\author{
Jie-Jie Sun, Sen Xu, Zhong-Hua He, Xiu-Zhen Shi, Xiao-Fan Zhao and Jin-Xing Wang* \\ Shandong Provincial Key Laboratory of Animal Cells and Developmental Biology, School of Life Sciences, Shandong \\ University, Jinan, China
}

OPEN ACCESS

Edited by:

Linsheng Song,

Dalian Ocean University, China

Reviewed by:

Kunlaya Somboonwiwat,

Chulalongkorn University, Thailand

Jorge Galindo-Villegas,

Universidad de Murcia, Spain

${ }^{*}$ Correspondence: Jin-Xing Wang jxwang@sdu.edu.cn

Specialty section: This article was submitted to

Comparative Immunology, a section of the journal

Frontiers in Immunology

Received: 13 April 2017 Accepted: 31 August 2017 Published: 20 September 2017

Citation:

Sun J-J, Xu S, He Z-H, Shi X-Z, Zhao X-F and Wang J-X (2017)

Activation of Toll Pathway is Different between Kuruma Shrimp and Drosophila.

Front. Immunol. 8:1151. doi: 10.3389/fimmu.2017.01151
The Toll pathway is essential for inducing an immune response to defend against bacterial invasion in vertebrates and invertebrates. Although Toll receptors and the transcription factor Dorsal were identified in different shrimp, relatively little is known about how the Toll pathway is activated or the function of the pathway in shrimp antibacterial immunity. In this study, three Tolls (Toll1-3) and the Dorsal were identified in Marsupenaeus japonicus. The Toll pathway can be activated by Gram-positive $\left(\mathrm{G}^{+}\right)$and Gram-negative $\left(\mathrm{G}^{-}\right)$bacterial infection. Unlike Toll binding to Spätzle in Drosophila, shrimp Tolls could directly bind to pathogen-associated molecular patterns from $\mathrm{G}^{+}$and $\mathrm{G}^{-}$bacteria, resulting in Dorsal translocation into nucleus to regulate the expression of different antibacterial peptides (AMPs) in the clearance of infected bacteria. These findings suggest that shrimp Tolls are pattern recognition receptors and the Toll pathway in shrimp is different from the Drosophila Toll pathway but identical with the mammalian Toll-like receptor pathway in its activation and antibacterial functions.

Keywords: Toll, Dorsal, antimicrobial peptides, Vibrio anguillarum, Staphylococcus aureus, Marsupenaeus japonicas

\section{INTRODUCTION}

Host defense is known to mainly rely on innate immunity in invertebrates. Studies on the innate immune system of invertebrates have garnered much information regarding the underlying mechanisms of resistance to microbial invasion. The Toll pathway plays important functions in innate immunity against infectious pathogens in vertebrates and invertebrates. Activation of the Toll pathway is different between vertebrates and invertebrates, in which the former is directly activated by Toll-like receptors (TLRs) binding to various pathogen-associated molecular patterns (PAMPs) from different pathogens, and the latter is indirectly activated by pathogen infection where Toll receptors bind to the cytokine-like molecule Spätzle but not to PAMPs. Tolls and TLRs from vertebrates and invertebrates are characterized by an extracellular domain containing leucine-rich repeats (LRRs), a transmembrane domain, and a cytoplasmic tail that contains a conserved region called the Toll/ IL-1 receptor (TIR) domain. In humans, 10 TLRs function as pattern recognition receptors (PRRs), binding specifically to PAMPs from bacteria, fungi, and viruses (1). TLRs are present in the plasma membrane (TLR1, TLR2, TLR4, TLR5, and TLR6) and endosome (TLR3, TLR7, TLR8, and TLR9) of leukocytes. Among these, TLRs in the plasma membrane mainly recognize lipopeptides, lipoteichoic acid, lipopolysaccharide (LPS), or bacterial flagellin and the endosome TLRs mainly recognize different nucleic acid patterns, such as single-stranded RNA, unmethylated CpG motifs that exist in both viral and bacterial DNA $(2,3)$. 
In Drosophila, nine Toll genes have been identified (4), and the first identified Toll (Toll1) is the receptor for the Toll pathway. Toll2 has a minor role in the antibacterial immunity (5), and Toll5 and Toll9 can activate the antifungal gene drosomycin expression $(6,7)$. However, unlike TLRs in mammalian, Toll is not a direct PRR in insects (8). Rather, pathogen infection is sensed by extracellular recognition factors and initiates proteolytic cascades that hydrolyze the ligand of the Toll receptor proSpätzle to Spätzle as an active form binding to Toll receptor for the Toll pathway activation (9-11). In Drosophila, the Toll pathway responds to fungal and $\mathrm{G}^{+}$ bacterial infections (11-17). Once activated, a cassette of proteins consisting of MyD88, Tube, and Pelle is recruited, and this complex is able to trigger the degradation of Cactus, freeing Dorsal, and Dorsal-related immunity factor (DIF) to enter the nucleus (18-20) to regulate the expression of AMPs, such as drosomycin $(16,21-25)$. The Toll pathway also functions in cellular immunity, including phagocytosis of microbes, encapsulation and killing of parasites (26). A recent study found that Drosophila Toll7 acts as a PRR by interacting with vesicular stomatitis virus to induce an effector program that converges on antiviral autophagy (27).

Tolls identified in Litopenaeus vannamei $(28,29)$, Fenneropenaeus chinensis (30), Penaeus monodon (31,32), Marsupenaeus japonicus (33), and Procambarus clarkii $(34,35)$ play important roles in shrimp innate immunity. LvToll1-3 responded to Vibrio alginolyticus and WSSV infections in L. vannamei (29). FcToll and MjToll respond to various immune challenges $(30,33)$. PcToll and PcToll2 regulate AMP expression after challenged with Vibrio anguillarum in P. clarkii $(34,35)$. LvToll in L. vannamei regulates AMP expression after challenge with $V$. anguillarum and Micrococcus lysodeikticus (28). The transcription factor Dorsal from L. vannamei (36), F. chinensis (37), and M. japonicus (38) in the shrimp Toll pathway have been reported to contribute to shrimp AMP regulation. Although previous studies have found that shrimp Tolls are involved in the regulation of AMP expression, it is unclear whether activation of the Toll pathway is pathogen specific and whether Toll directly bind to pathogens for activation. In this study, we systematically examined the activation and function of the Toll pathway in shrimp immunity and found that activation of the Toll pathway in shrimp was different from that in insects.

\section{MATERIALS AND METHODS}

\section{Bacterial Challenge and Tissue Collection}

Kuruma shrimp M. japonicus (8-10 g per shrimp) purchased from an aquatic product market in Jinan, Shandong Province, China were nurtured in laboratory tanks filled with seawater at $24^{\circ} \mathrm{C}$. For bacterial challenge assays, each shrimp was injected in the abdominal segment with $V$. anguillarum or Staphylococcus aureus $\left(2 \times 10^{7} \mathrm{CFU}\right.$ per shrimp). Hemolymph was collected from the ventral sinus using a syringe with equal volume of anticoagulant buffer $(0.45 \mathrm{M}$ of $\mathrm{NaCl}, 10 \mathrm{mM}$ of $\mathrm{KCl}, 10 \mathrm{mM}$ of EDTA, and $10 \mathrm{mM}$ of HEPES, $\mathrm{pH} 7.45$ ), and then immediately centrifuged at $800 \times g$ for $15 \mathrm{~min}$ at $4^{\circ} \mathrm{C}$ to isolate the hemocytes used for total RNA extraction, protein extraction, western blotting analyses, and immunocytochemistry. The organs, such as the heart, hepatopancreas, gills, stomach and intestine, were also collected and used for total RNA extraction.

\section{Gene Cloning}

Sequences of the Toll (Toll1-3) and Dorsal were obtained from transcriptome sequencing of hemocytes of M. japonicas (BGI, China). To confirm the sequences, specific primers MjToll3F1/-R1 and MjToll3-F2/-R2 (Table 1) were designed to amplify the nucleotide sequences from the hemocytes. Polymerase chain reaction (PCR) was performed using cDNA of hemocytes as a template: $94^{\circ} \mathrm{C}$ for $3 \mathrm{~min} ; 35$ cycles of $94^{\circ} \mathrm{C}$ for $30 \mathrm{~s}, 53^{\circ} \mathrm{C}$ for $45 \mathrm{~s}$, and $72^{\circ} \mathrm{C}$ for $90 \mathrm{~s}$; and a final step of $72^{\circ} \mathrm{C}$ for $10 \mathrm{~min}$. The obtained PCR products were run on the agarose gel electrophoresis and then they were purified using a gel purification kit (Sangon, Shanghai, China). The obtained PCR products were first inserted into pMD-18T vector and then transformed into competent DH5 $\alpha$ cells. Positive clones were sequenced by the Sangon Company (Shanghai, China), and the sequence was analyzed with online translation and BLAST analysis.

TABLE 1 | Sequences of the primers used in this study.

\begin{tabular}{|c|c|}
\hline Primer & Sequence $\left(5^{\prime}-3^{\prime}\right)$ \\
\hline \multicolumn{2}{|c|}{ Gene clone } \\
\hline Toll3-F1 & СTACTTGCAGTGAAATAATTGC \\
\hline Toll3-R1 & GTACGAAATGGTAATCAAACAC \\
\hline Toll3-F2 & GTGTITGATTACCATITCGTAC \\
\hline Toll3-R2 & GCACGACCACCAGGAGAAACA \\
\hline
\end{tabular}

Tissue distribution and expression pattern analysis

Toll1-RT-F GAGTTCAGCGGCGTGGTA

Toll1-RT-R ACGGAGGCGTTGAGGGA

Toll2-RT-F GGTCCCAGTTCTGTAAGG

Toll2-RT-R TAGGCACATTCGGATAAA

Toll3-RT-F CTGGTCGGTITCCTGGTGGC

Toll3-RT-R CCAACCTGGGCACCACATACTG

Dorsal-RT-F GCAATGCTGGTAACCTGGCTA

Dorsal-RT-R CTATGGGATITGGTCAATACAC

ALF-B1-RT-F CGGTGGTGGCCCTGGTGGCACTCTTCG

ALF-B1-RT-R GACTGGCTGCGTGTGCTGGCTTCCCCTC

ALF-C2-RT-F TCCTGGTGGTGGCAGTGGCT

ALF-C2-RT-R TGCGGGTCTCGGCTTCTCCT

Crut-1-RT-F TGCTCAGAACTCCCTCCACC

Crut-1-RT-R TTGAATCAGCCCATCGTCG

Crut-3-RT-F CTCCACCACTCTCGCACTAACA

Crui-3-RT-R TGATGGTCTCAGATTGGGGC

Actin-RT-F CAGCCTTCCTTCCTGGGTATGG

Actin-RT-R GAGGGAGCGAGGGCAGTGATT

Recombinant expression

Toll1-Ex-F TACTCAGAATTCATGTCCATAGTGACGGGAGTCTGG

Toll1-Ex-R TACTCACTCGAGTTAGATCACTGTACTGGCGATGAT

Toll2-Ex-F TACTCAGAATTCATGCACACCATGTTAGCCAGC

Toll2-Ex-R TACTCACTCGAGTTATGGACAGATGGTATATTC

Toll3-Ex-F TACTCAGGATCCATGTGGAGTGTTAGCCGCAGAGAT

Toll3-Ex-R TACTCAGTCGACTTAGTTCTCCACTAGTCTCCACAC

\section{RNA interference}

Toll1-RNAi-F GCGTAATACGACTCACTATAGGCCATCCTTCTGCCACCTAA

Toll1-RNAi-R GCGTAATACGACTCACTATAGGAATCTGATTTGACAAGTTCC

Toll2-RNAi-F GCGTAATACGACTCACTATAGGTAAAGTCCTTGATGTGCGAG

Toll2-RNAi-F GCGTAATACGACTCACTATAGGTGTATAAGTTCTTGTGGGTGT

Toll3-RNAi-F GCGTAATACGACTCACTATAGGTGGAGCGTGGAGACAGGCCC

Toll3-RNAi-F GCGTAATACGACTCACTATAGGCTGTTGACACTGTACTTGT

Dorsal-RNAi-F GCGTAATACGACTCACTATAGGCCATAGAGCTAGATA

Dorsal-RNAi-R GCGTAATACGACTCACTATAGGTCAGTACCCAAGTGT

GFP-RNAi-F GCGTAATACGACTCACTATAGGTGGTCCCAATTCTCGTGGAAC

GFP-RNAi-R GCGTAATACGACTCACTATAGGCTTGAAGTTGACCTTGATGCC 


\section{Semiquantitative RT-PCR and Real-time Quantitative RT-PCR (qPCR)}

Total RNAs digested with RNase-free DNase I reverse transcribed using first-strand cDNAs, which were diluted 10-fold in nucleasefree water and used as templates for tissue distribution analysis by semiquantitative RT-PCR with primers F and R (Table 1). PCR was performed as follows: 1 cycle of $95^{\circ} \mathrm{C}$ for $2 \mathrm{~min} ; 30$ cycles of $95^{\circ} \mathrm{C}$ for $30 \mathrm{~s}, 54^{\circ} \mathrm{C}$ for $45 \mathrm{~s}$, and $72^{\circ} \mathrm{C}$ for $25 \mathrm{~s}$; and a final step of $72^{\circ} \mathrm{C}$ for $10 \mathrm{~min}$. $\beta$-Actin amplified with the primers $\mathrm{F}$ and $\mathrm{R}$ (Table 1) was used as internal control.

Total RNAs from the hemocytes of shrimp (8-10 g per shrimp) at $3,6,12,24$, and $48 \mathrm{~h}$ after challenged with $V$. anguillarum or S. aureus were treated by RNase-free DNase I, and then were used to reverse transcribe the first-strand CDNAs as templates for qPCR after 20-fold dilution. $\beta$-Actin was used as internal control. qPCR was performed in a C1000 thermal cycler (Bio-Rad, USA) with a total volume of $10 \mu \mathrm{l}$ containing $4 \mu \mathrm{l}$ of $2 \times$ Ultra SYBR mixture (with ROX, CWBio, Beijing, China), $1 \mu$ l of 1:20 diluted cDNA, $2 \mu \mathrm{l}$ of $1 \mu \mathrm{M}$ forward primer, and $1 \mu \mathrm{l}$ of $1 \mu \mathrm{M}$ reverse primer. The PCR procedure was performed as follows: $95^{\circ} \mathrm{C}$ for $10 \mathrm{~min} ; 40$ cycles of $95^{\circ} \mathrm{C}$ for $15 \mathrm{~s}$ and $60^{\circ} \mathrm{C}$ for $1 \mathrm{~min}$; and melting from 65 to $95^{\circ} \mathrm{C}$. The qPCR was repeated three times, and the data were analyzed using the $2^{-\Delta \Delta C T}$ method. Data were statistically analyzed using the unpaired $t$-test, and a significant difference was accepted at $p<0.05$.

\section{Western Blotting Analysis}

Proteins were extracted from the hemocytes of normal shrimp and bacterial challenged shrimp. For extraction of cytoplasmic and nuclear proteins from hemocytes, we used the Nuclear Protein Extraction Reagent Kit (BioTeke, China), following the manufacturer's instruction. The obtained protein samples from shrimp hemocytes were analyzed by $10 \%$ SDS-polyacrylamide gel electrophoresis and transferred onto a nitrocellulose membrane. The nitrocellulose membrane was blocked for $1-2 \mathrm{~h}$ with $3 \%$ nonfat milk in TBST (100 mM NaCl, pH 7.5, $10 \mathrm{mM}$ Tris-HCl, and $0.02 \%$ Tween) and then incubated with 1/200 diluted anti-Dorsal in TBST with $3 \%$ non-fat milk for $3 \mathrm{~h}$ at room temperature. After washing three times for $5 \mathrm{~min}$ with TBST, alkaline phosphataseconjugated goat anti-rabbit IgG (1/10,000 diluted in TBST) was added. The membrane was incubated for $3 \mathrm{~h}$, and unbound IgG was then washed three times for $5 \mathrm{~min}$. The membrane was visualized by the reaction system ( $10 \mathrm{ml}$ of TBS, with $45 \mu \mathrm{l}$ of NBT and $35 \mu \mathrm{l}$ of BCIP) in the dark for 5-20 min. The Dorsal antibody was prepared in our lab, and the detailed method has been previously described (38). The NF-kB P65 (Serine276) antibody purchased from ABGENT (San Diego, CA, USA) was used to detect Dorsal phosphorylation in Toll1-3-silenced shrimp by western blotting analyses.

\section{Far-Western Overlay Assay}

A far-Western overlay assay was performed to determine the interaction of rTolls with LPS or PGN. The rTolls were subjected to SDS-PAGE, and then the proteins in the SDS-PAGE gel were transferred onto a nitrocellulose membrane. The membrane was blocked for 1-2 $\mathrm{h}$ with $3 \%$ non-fat milk in TBST, then incubated with LPS or PGN. After washed three times, the membrane was incubated with purified rCC-CL $(0.1 \mathrm{mg} / \mathrm{ml})$, a kind of C-type lectin from M. japonicus which could interact with LPS and PGN for $3 \mathrm{~h}$. After being washed three times with TBST, the membrane was incubated with 1:300-diluted antiserum to rCC-CL (prepared in our laboratory) for $4 \mathrm{~h}$. After washed three times, the membrane was incubated with alkaline phosphataseconjugated goat anti-rabbit IgG (1/10,000 diluted in TBST). The membrane was washed again three times with $10 \mathrm{ml}$ of TBST. The membrane was visualized by the reaction system $(10 \mathrm{ml}$ of TBS, with $45 \mu \mathrm{l}$ of NBT and $35 \mu \mathrm{l}$ of BCIP) in the dark for 5-20 min.

\section{Immunocytochemistry}

Hemolymph was collected from at least three shrimp (8-10 g per shrimp) using a $5 \mathrm{ml}$ syringe preloaded with $1 \mathrm{ml}$ of anticoagulant and $4 \%$ paraformaldehyde (1:1). The hemocytes were collected by centrifugation at $700 \times g$ for $3 \mathrm{~min}$ at $4^{\circ} \mathrm{C}$, and then washed with PBS (140 mM NaCl, $10 \mathrm{mM}$ sodium phosphate, $\mathrm{pH}$ 7.4) three times and then dropped onto slides. The slides with hemocytes were incubated in $0.2 \%$ Triton $\mathrm{X}-100$ at $37^{\circ} \mathrm{C}(5 \mathrm{~min})$, washed with PBS five times to remove Triton X-100, and then blocked by $1 \%$ bovine serum albumin (BSA, dissolved in PBS) at $37^{\circ} \mathrm{C}$ for $30 \mathrm{~min}$. Subsequently, anti-Dorsal was added on the slides, which were incubated overnight at $4^{\circ} \mathrm{C}$. After the slides were washed with PBS five times and incubated with $3 \%$ BSA, the second antibody goat anti-rabbit-Alexa Fluor 488 (1:1,000 diluted in 3\% BSA) was added, and the slides were incubated for $1 \mathrm{~h}$ at $37^{\circ} \mathrm{C}$. Nuclei of the hemocytes were stained using $4^{\prime}$,6-diamidino-2-phenylindole (DAPI, $1 \mu \mathrm{g} / \mathrm{ml}$, AnaSpec Inc., San Jose, CA, USA) for $10 \mathrm{~min}$ and then washed with PBS again. Hemocytes were observed using an Olympus microscope (Olympus BX51, Tokyo, Japan). We use the ImageJ (MBF ImageJ) (http://imagej.net/mbf/installing_imagej. $\mathrm{htm}$ ) to calculate the colocalization percentage of Dorsal with nucleus stained with DAPI. First we open the picture and choose Image-Color-Split channels, and close the no need channels, and then click Plugins-colocalization analysis-colocalization threshold-OK. We then get the Rcoloc value.

\section{Recombinant Expression and Purification}

Individual primer pairs Toll1-Ex-F/-R, Toll2-Ex-F/-R, and Toll3Ex-F/-R (Table 1) containing Eco RI and Xho I sites were used to amplify the fragments encoding mature Toll1, 2 , and 3 proteins. The fragments were inserted into the pGEX4T-1 or pET32a (+) vector, respectively, and then transformed into Escherichia coli BL21 (DE3) cells for overexpression. The recombinant proteins were purified using affinity chromatography with GST-resin (GenScript, Nanjing, China) or His-Bind resin $\left(\mathrm{Ni}^{2+}\right.$-resin; Novagen, Darmstadt, Germany), according to the manufacturer's instructions.

\section{Binding Assays}

Bacteria including $\mathrm{G}^{+}$bacteria (S. aureus ATCC 6538 and Bacillus subtilis ATCC 9372) and $\mathrm{G}^{-}$bacteria (V. anguillarum and E. coli ATCC 8099) were selected to test the binding ability of recombinant Toll1-3 (rToll1-3). The binding assay to bacteria was 
performed according to a previous method (39). After culturing overnight at $37^{\circ} \mathrm{C}$, the bacteria were collected, and washed with TBS (100 mM Tris-HCl, $15 \mathrm{mM} \mathrm{NaCl}, \mathrm{pH}$ 7.5). The collected bacteria $\left(2 \times 10^{6} \mathrm{CFU}\right)$ were incubated with $100 \mu \mathrm{g}$ of purified rToll1, 2, or 3 at $28^{\circ} \mathrm{C}$ for $1 \mathrm{~h}$, washed with TBS four times, and eluted by $10 \%$ SDS for $1 \mathrm{~min}$. The eluted proteins were preloaded onto $12.5 \%$ SDS-PAGE and then analyzed using western blotting analyses. The eluted proteins were collected and used for SDS-PAGE and western blotting using anti-His as the primary antibody.

ELISA was used to test the binding activity of rToll1-3 to several bacterial cell wall components, including PGN (from S. aureus; Sigma, St. Louis, MO, USA) and LPS (from E. coli 055:B5 Sigma, St. Louis, MO, USA). Polysaccharides were dissolved in distilled water at $80 \mu \mathrm{g} / \mathrm{ml}$ concentration and sonicated for $3 \mathrm{~s} \times 15 \mathrm{~s}$ on ice, and $50 \mu \mathrm{l}(4 \mu \mathrm{g})$ were coated to each well of the plate as previously described (39). The purified rToll1, 2, or 3 was diluted in TBS to different concentrations: $0.005,0.01,0.05,0.1,0.5$, and $1 \mu \mathrm{M}$. The plates were incubated with the recombinant protein for $3 \mathrm{~h}$ at room temperature, and then washed with TBS four times and incubated with mouse monoclonal anti-His antibody (1:2,000 dilution in TBS with $0.1 \mathrm{mg} / \mathrm{ml} \mathrm{BSA}$ ) for $1 \mathrm{~h}$ at $37^{\circ} \mathrm{C}$. The plates were then washed again and incubated with alkaline phosphatase-conjugated horse anti-mouse IgG (1:3,000 dilution in TBS with $0.1 \mathrm{mg} / \mathrm{ml}$ BSA) for $1 \mathrm{~h}$ at $37^{\circ} \mathrm{C}$. Finally, $100 \mu \mathrm{l}$ of $p$-nitro-phenyl phosphate ( $1 \mathrm{mg} / \mathrm{ml}$ in $10 \mathrm{mM}$ diethanolamine and $0.5 \mathrm{mM} \mathrm{MgCl}_{2}$ ) was added to each well of the plate and incubated for $30 \mathrm{~min}$ at room temperature. The absorbance at $405 \mathrm{~nm}$ for each well was read using a plate reader (Bio-Tek Instruments). The binding assays were repeated three times.

\section{RNA Interference (RNAi)}

The Toll1, 2, and 3 Dorsal, cDNA fragments amplified separately by primer pairs Toll1-RNAi-F/-R, Toll2-RNAi-F/-R, Toll3RNAi-F/-R, Dorsal-RNAi-F/R (Table 1) were used as a template for dsRNA synthesis with the RNAi kit from Fermentas (Thermo Fisher Scientific, USA). The GFP cDNA fragment used for dsGFP synthesis was amplified using the primer pair GFP-RNAi-F/-R (Table 1). The assay for dsRNA synthesis was performed as previously described (40). The dsRNA (3 $\mu \mathrm{g} / \mathrm{g}$ shrimp) separate from Toll1-3 was injected into the abdominal segment of each shrimp (8-10 g per shrimp). To enhance the RNAi effect, the second injection of dsRNA ( $3 \mu \mathrm{g} / \mathrm{g})$ was injected at $12 \mathrm{~h}$ after the first injection. The $d s G F P$ was used as control. Hemocytes were collected from treated shrimp at $24 \mathrm{~h}$ after the second injection, and total RNA was extracted and detected by qPCR using the corresponding primer pairs (Table 1) to confirm the RNAi effect.

Twenty microliters of $S$. aureus or V. anguillarum $\left(2 \times 10^{7} \mathrm{CFU}\right.$ per shrimp) were injected into the Toll1-, Toll2-, and Toll3-silenced shrimp, and Dorsal-silenced shrimp. At $6 \mathrm{~h}$ after bacterial injection, hemocytes was collected from at least three shrimp. Total RNA was extracted and reverse transcribed into first-stand cDNA, which was diluted 20-fold and used as the template for qPCR analysis as previously described. The assays were repeated at least three times.

\section{RESULTS}

\section{Tissue Distribution and Expression Patterns of Toll1-3}

Three Tolls (Toll1, 2, and 3) were identified in kuruma shrimp and accession number of Toll1 is AB333779.1, Toll2 is AB385869.1, and Toll3 is MF360946. The domain architectures of Toll1-3 were analyzed, and they all contained an extracellular domain with different tandem LRRs (13-24 LRRs) and a cytoplasmic tail that contains a TIR domain (Figure 1A). The tissue distributions of Toll1-3 in hemocytes, heart, hepatopancreas, gill, stomach, and intestine were analyzed by semiquantitative RT-PCR and the results showed that Toll1-3 were distributed in all tested tissues, but Toll1 exhibited low expression levels in the stomach and intestine (Figure 1B). Expression patterns of Toll1-3 after S. aureus and $V$. anguillarum challenge were analyzed by qPCR. The results showed that in hemocytes Toll1-2 were significantly increased at 12 and $24 \mathrm{~h}$ and Toll 3 was significantly increased at $24 \mathrm{~h}$ after S. aureus challenge (Figure 1C). Toll1-3 were significantly increased at $24 \mathrm{~h}$ after $V$. anguillarum challenge (Figure 1D). Taken together, these results suggested that the Toll pathway might be related to $\mathrm{G}^{+}$and $\mathrm{G}^{-}$bacterial infection in shrimp.

\section{Dorsal Translocated into the Nucleus after Bacterial Challenge}

To clarify whether bacterial challenge activated the Toll pathway, Dorsal translocation into nucleus was detected in hemocytes of shrimp challenged with S. aureus and V. anguillarum. The results showed that Dorsal translocated from the cytoplasm into the nucleus in hemocytes at $1 \mathrm{~h}$ after $S$. aureus and V. anguillarum challenge (Figure 2A, a). Western blotting analyses were performed using cytoplasmic or nuclear proteins from the hemocytes of shrimp after challenge with $S$. aureus and $V$. anguillarum. The results showed that Dorsal in the nucleus increased after S. aureus or V. anguillarum challenge (Figure 2B). Molecular mass of native Dorsal was confirmed by western blotting using Dorsal antibody (Figure 2C). These results indicated that bacterial challenge could induce Dorsal translocation into nucleus in shrimp.

\section{Toll1-3 Are Involved in Regulating Dorsal Translocation into the Nucleus after Bacterial Challenge}

To study whether Toll1-3 were involved in regulating Dorsal translocation, RNAi of Tolls was performed, and Dorsal translocation was detected using an immunocytochemical assay. These results showed that after knockdown of Toll1-3 in shrimp (Figure 3A) following challenge with S. aureus or V. anguillarum, most Dorsal signals were detected in the cytoplasm of hemocytes, suggesting that Dorsal translocation into the nucleus was inhibited in Toll1-3-silenced shrimp challenged with S. aureus or $V$. anguillarum (Figures 3B,C). In addition, cytoplasmic or nuclear proteins were extracted for western blotting analysis, and the results showed that Dorsal in the nucleus of hemocytes was decreased in Toll1-3-silenced shrimp after challenge with $S$. aureus or $V$. anguillarum at $1 \mathrm{~h}$ compared with the control (Figures 3D,E). The phosphorylation Dorsal antibody was used 

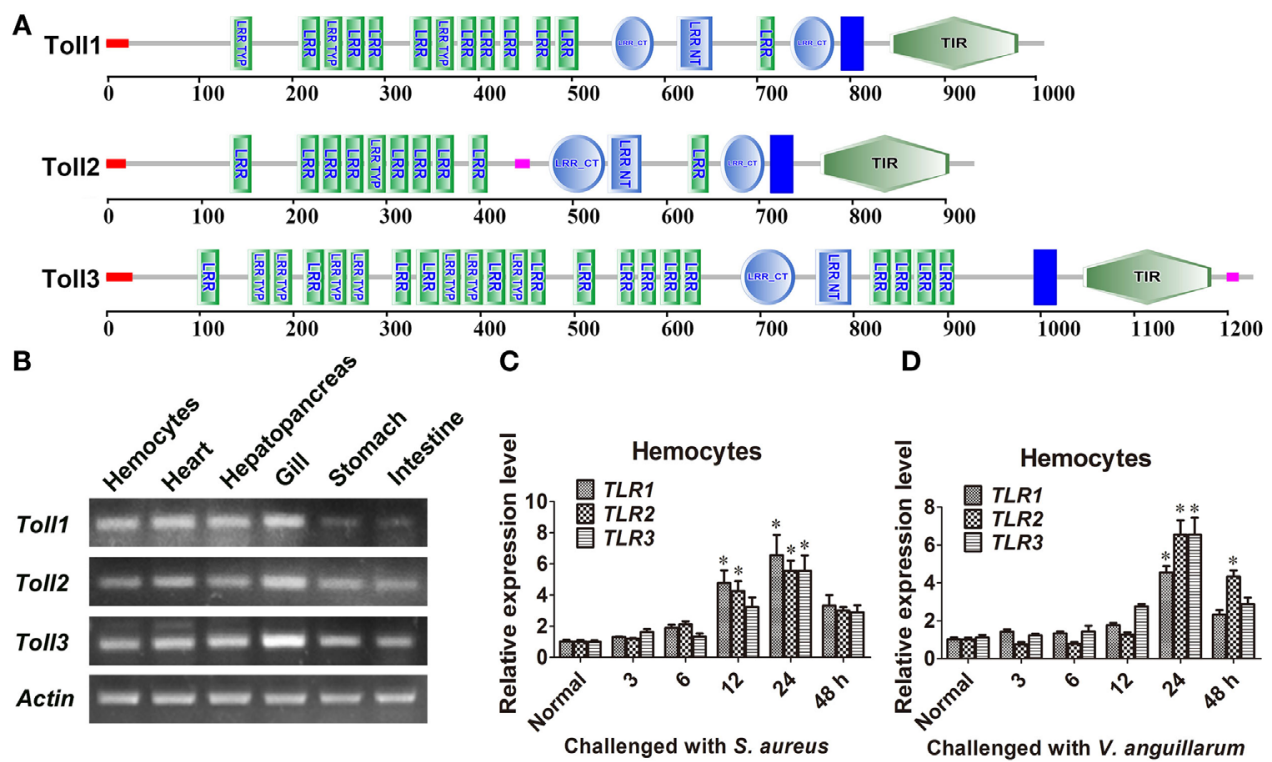

FIGURE 1 | Toll1-3 were ubiquitously distributed in shrimp and upregulated after bacterial challenge. (A) Domain architectures of Toll 1 (GenBank accession no. AB333779.1), Toll 2 (AB385869.1), and Toll 3 (MF360946) were predicted by online software SMART (http://smart.embl-heidelberg.de/) using the Toll sequences of kuruma shrimp. (B) Tissue distributions of Toll1-3 in hemocytes, heart, hepatopancreas, gill, stomach, and intestine were analyzed by RT-polymerase chain reaction (PCR) $\beta$-Actin was used as the internal control. (C,D) Expression patterns of Toll1-3 in hemocytes at different time points after Staphylococcus aureus (C) and Vibrio anguillarum (D) challenge were detected by qPCR. The expression patterns of $\beta$-Actin were used as internal control. Significant differences are indicated with asterisks $\left({ }^{*} p<0.05\right)$.

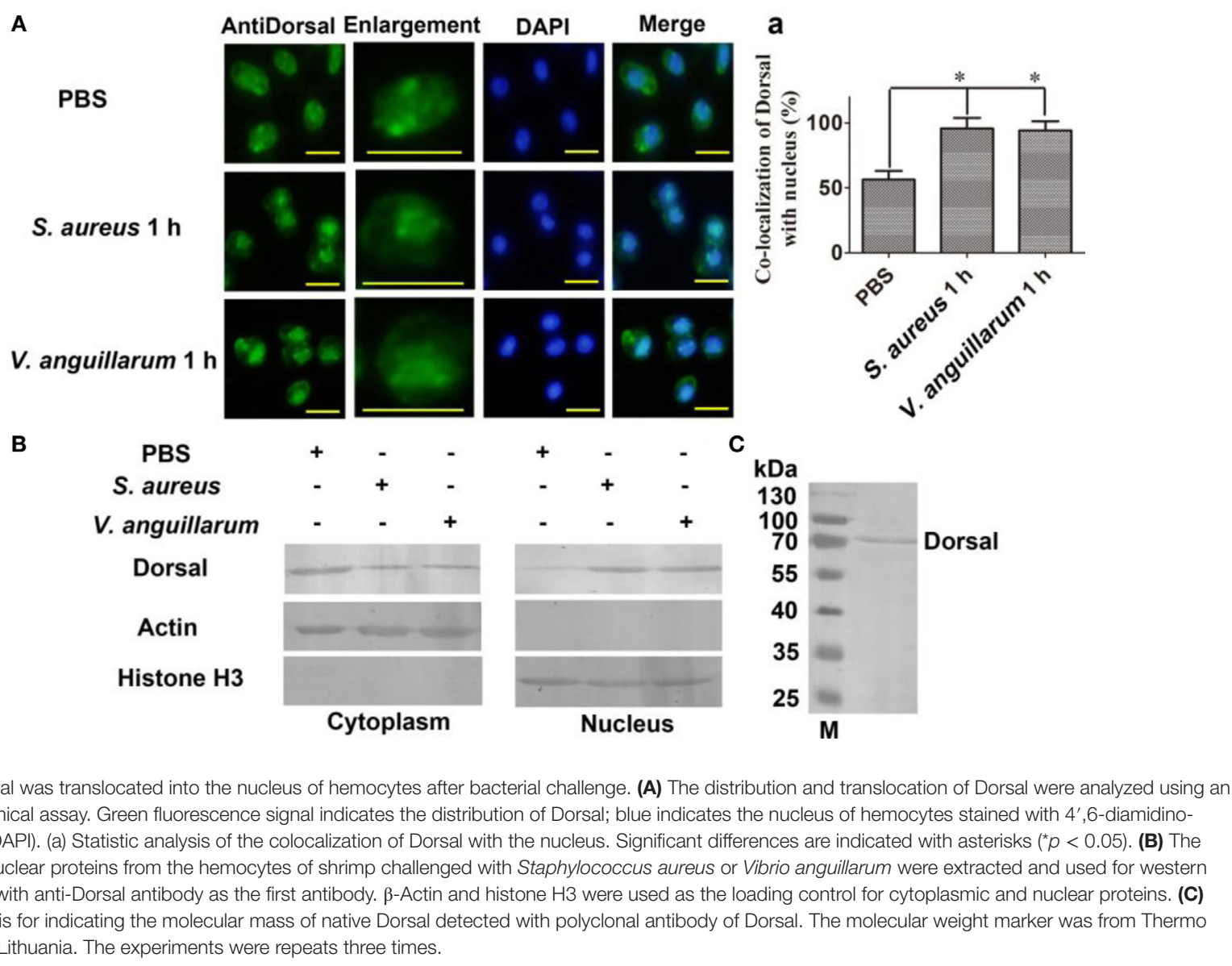




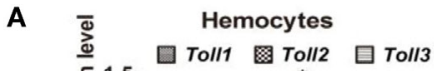

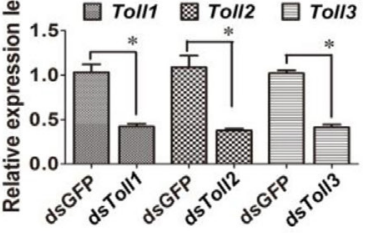

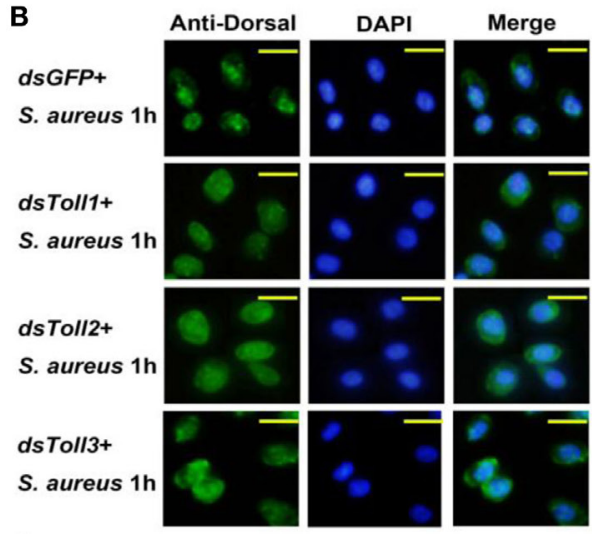

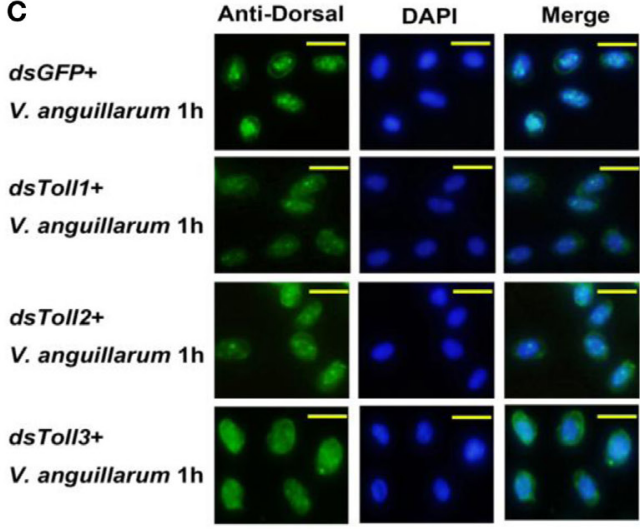

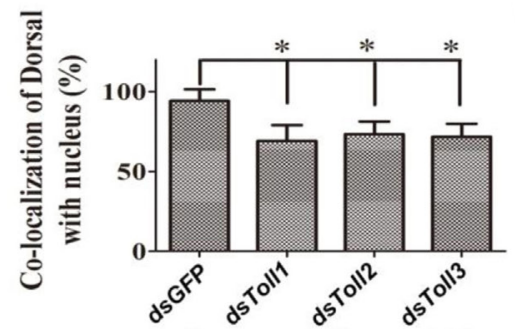

$S$. aureus challenge at $1 \mathrm{~h}$

D

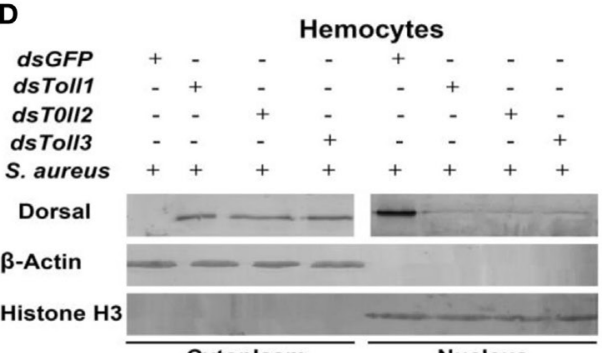

Cytoplasm

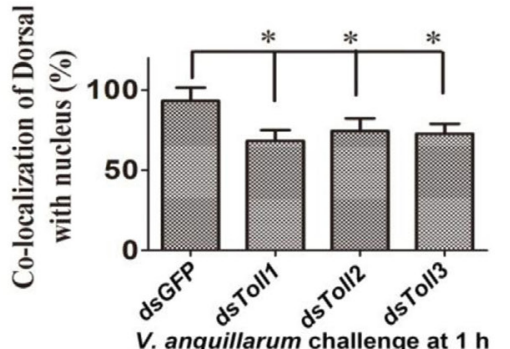

E

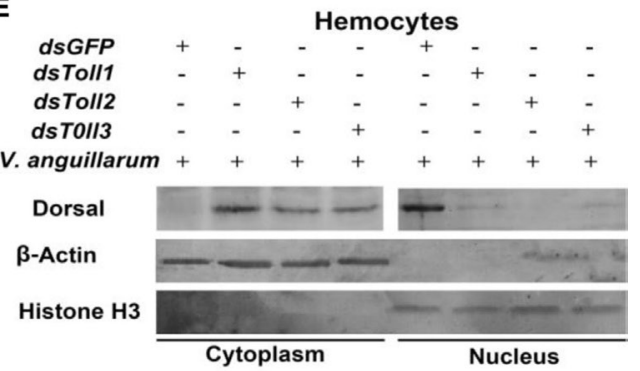

G

F

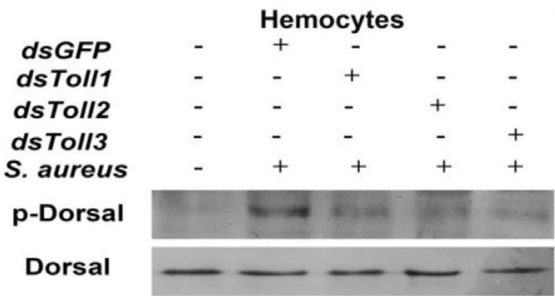

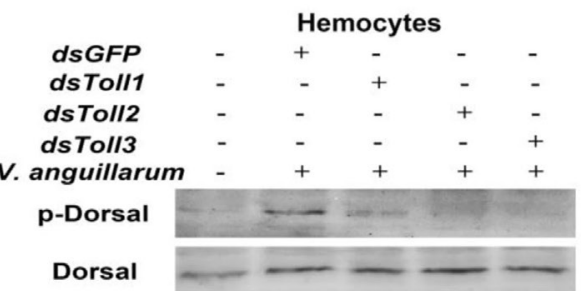

FIGURE 3 | Toll1-3 regulate Dorsal translocation and phosphorylation. (A) The RNA interference (RNAi) efficiency of Toll1, Toll2, and Toll3 was analyzed by qPCR.

(B) Dorsal translocation in hemocytes of Toll1,2, and 3-silenced shrimp challenged with Staphylococcus aureus was detected using an immunocytochemical assay. (b) Statistic analysis of the colocalization of Dorsal with the nucleus in hemocytes with WCIF ImageJ software. (C) Dorsal translocation in hemocytes of Toll1-3silenced shrimp challenged with Vibrio anguillarum was analyzed using an immunocytochemical assay. (c) Statistic analysis of the colocalization of Dorsal with the nucleus in hemocytes with WCIF ImageJ software. The dsGFP was used as the control. Significant differences are indicated with asterisks $\left({ }^{*} p<0.05\right)$.

(D,E) Cytoplasmic or nuclear proteins were extracted from the hemocytes of Toll1-3-silenced shrimp challenged with S. aureus (D) or V. anguillarum (E), and the samples were used for western blotting analysis with Dorsal antibody. $\beta$-Actin and histone $\mathrm{H} 3$ were used as the loading control for the cytoplasmic or nuclear proteins. (F,G) Dorsal phosphorylation was detected in hemocytes from Toll1-3-silenced shrimp challenged with S. aureus (F) or V. anguillarum (G) with phospho-

Dorsal antibody. The dsGFP was used as the control. 
to detect phosphorylated Dorsal in hemocytes, and the results showed that phosphorylation of Dorsal was inhibited in Toll1-3silenced shrimp challenged with $S$. aureus and $V$. anguillarum at $1 \mathrm{~h}$ (Figures 3F,G). Taken together, these results indicated that Toll1, 2, and 3 affected Dorsal translocation and phosphorylation, suggesting that activation of the Toll pathway by bacterial challenge occurs via Toll receptors.

\section{rToll1-3 Bind to Microorganisms by Binding to Polysaccharides}

To determine how the bacterial challenge activates the Toll pathway, the bacterial binding activities of Toll1-3 were analyzed. The extracellular domain containing LRRs of Toll1, 2, and 3 were recombinantly expressed for bacterium-binding assays (Figures 4A1C1). The results showed that $r$ Toll1 -3 bound to several $\mathrm{G}^{+}$bacteria (S. aureus and B. subtilis) and $\mathrm{G}^{-}$bacteria ( $V$. anguillarum and E. coli) (Figures 4A2-C2). The ELISA assay was carried out to detect the binding activity of rTolls to glycans including PGN and LPS. The results showed that rToll1, 2, and 3 bound to PGN and LPS, in a concentration-dependent manner (Figures 4A3-C3). To further confirm that Toll1-3 could interact with PGN or LPS, a kind of far-western assay was performed. The results showed that rToll1-3 could interact with PGN and LPS (Figures 4D,E). All above results suggested that rToll1-3 could directly bind to different bacteria by binding to the polysaccharides on their surfaces.

\section{Toll Pathway Regulates the Transcription of AMP Genes}

To further analyze the function of the Toll pathway, we detected if Toll1-3 affected Dorsal translocation and AMP expression (readout of the pathway). First, the expression of AMPs was analyzed after challenge with $S$. aureus and $V$. anguillarum at $6 \mathrm{~h}$. The results showed that expression of $A L F-D 2, A L F-B 1, A L F-C 2$, CruI-1, and CruI-3 were significantly upregulated after bacterial challenge (Figures 5A,B). Next, AMP expression in Dorsalknockdown (Figure 5C) shrimp was detected after challenge with $S$. aureus and $V$. anguillarum. The results showed that the expression of ALF-B1,ALF-C2, CruI-1, and CruI-3 was not significantly induced in Dorsal-knockdown shrimp challenged with $S$. aureus or $V$. anguillarum, but the expression of ALF-D2 was not affected in the shrimp (Figures 5D,E). Next, AMP expression in Toll1-3-knockdown shrimp was detected after challenge with $S$. aureus or $V$. anguillarum. These results revealed that the expression of $A L F-B 1, A L F-C 2, C r u I-1$, and CruI-3 was also not significantly induced in Toll1-3-knockdown (Figure 5C) shrimp after challenge with $S$. aureus or $V$. anguillarum. The expression of ALF-D2 was also not affected in the shrimp (Figures 5F-K). Taken together, these results suggested that activation of the Toll pathway could induce the expression of AMPs, including ALFB1, ALF-C2, CruI-1, and CruI-3 but not including ALF-D2.

\section{DISCUSSION}

In invertebrates, the innate immune system is extremely important in the host defense against pathogens. Toll pathway plays significant roles in innate immunity to defend against pathogens in mammals, insects, and shrimp $(41,42)$. In mammals, TLRs directly recognize PAMPs from pathogens and initiate signaling through $\mathrm{NF}-\kappa \mathrm{B}$, resulting in innate and adaptive immune responses $(43,44)$. Fungi and $\mathrm{G}^{+}$bacteria activate the Toll pathway of Drosophila. However, unlike TLRs in mammalian, Toll is not as a PRR in Drosophila, but secreted immune factors, such as peptidoglycan recognition proteins (PGRP-SA and PGRP-SD) and the GNBP family member GNBP1, act as PRRs by binding to $\beta$-1,3-glucans from fungi or peptidoglycan from $\mathrm{G}^{+}$bacteria and initiating proteolytic cascades (9). Binding of recognition proteins to either class of PAMPs triggers activation of the serine protease cascade to cleave proSpätzle to Spätzle, a functional Toll ligand that binds to the Toll receptor for signal pathway activation $(6,17)$. In shrimp, three Tolls have been identified and play important roles in antibacterial or antiviral defense (28-30, 33-35). The Toll receptors were reported to be involved in the regulation of AMP expression in shrimp after challenged with bacteria, but it is unclear how Toll signaling pathway is activated in shrimp. In this study, we found that both $\mathrm{G}^{+}$and $\mathrm{G}^{-}$bacteria could activate the Toll pathway and induce Dorsal translocation into the nucleus to regulate AMP expression, which is different from that in Drosophila that $\mathrm{G}^{+}$bacteria and fungi activate Toll pathway and induce DIF translocation into nucleus to regulate drosomycin expression. Further study found that the extracellular domain containing the LRRs of Toll1-3 could directly bind to $\mathrm{G}^{+}$and $\mathrm{G}^{-}$bacteria and also to LPS and PGN, which were similar to mammalian TLRs. Actually, the direct binding of Toll receptors to PAMPs was also reported in other invertebrates, such as Crassostrea gigas and Hyriopsis cumingii $(45,46)$. In C. gigas and H. cumingii, Tolls can directly bind to bacteria and also to LPS and PGN $(45,46)$. Thus, activation of the shrimp Toll pathway is different from that of Toll signaling in Drosophila but similar to that of the mammalian TLR pathway and some invertebrate Toll pathway. The Spätzles were also identified in shrimp, such as L. vannamei, P. monodon, F. chinensis, and M. japonicus. Although it is unclear how the proSpätzle activated, some studies found that it might be involved in regulation of AMP expression via Toll pathway (47-49). Our study also could not exclude Spätzle in shrimp involved in activation of Toll pathway. Taken together, two activation modes for the Toll signal pathway were identified in invertebrates, indirect activation, such as in Drosophila and other insects; and direct activation, such as in shrimp and mollusk animals. However, only one activation mode, direct activation of the TLR pathway, was identified in vertebrates.

The primary characteristic of insect innate immunity is rapid and massive induction of AMP genes. Released into insect hemolymph, AMPs then kill microbes or inhibit their growth by disrupting membrane integrity (50). Two pathways [Toll and Imd (immune deficiency) pathways] in Drosophila trigger the induction of AMP genes $(17,51)$. The Toll and Imd pathways each direct the expression of a set of AMP loci in response to infection. Some loci are pathway-specific: the Toll pathway regulates drosomycin expression and the Imd pathway regulates diptericin expression, whereas others can be induced by both the Toll and Imd pathways. In some cases, the responses are matched to the distinct inducers. For example, fungi and $\mathrm{G}^{+}$bacteria can activate Toll signaling, but not Imd signaling, which means that 


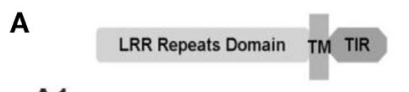

A1

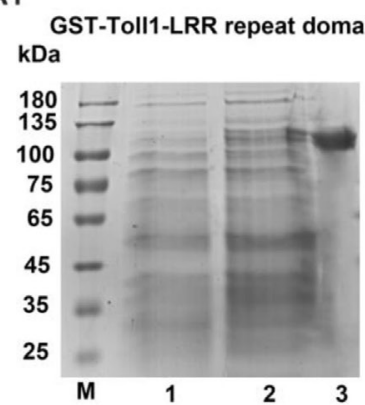

A2

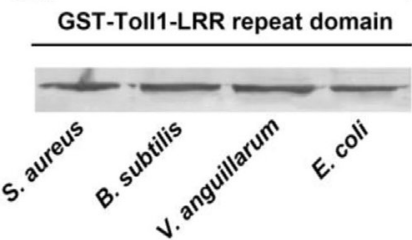

GST

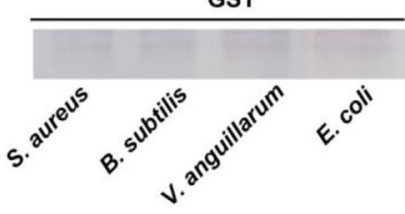

A3

GST-Toll1 repeat LRR domain

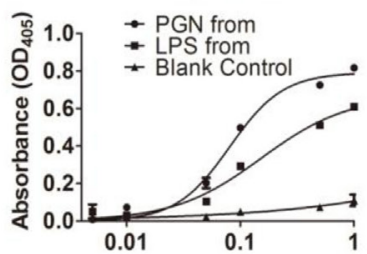

The concentration of protein $(\mu \mathrm{M})$
B

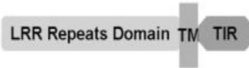

B1

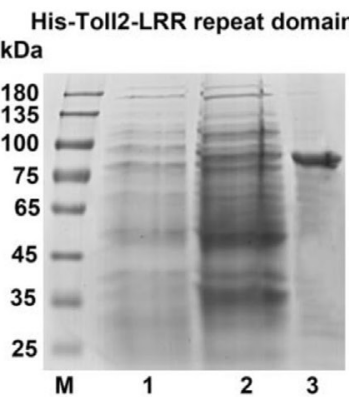

\section{C \\ LRR Repeats Domain}

C1

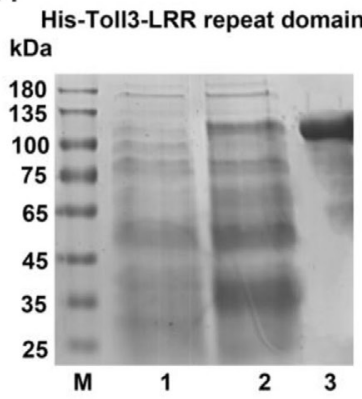

B2

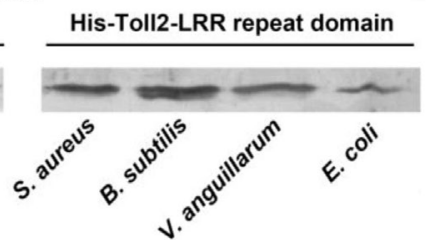

His

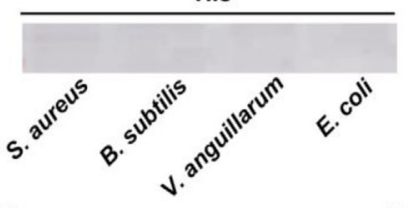

B3 His-Toll2 repeat LRR domain

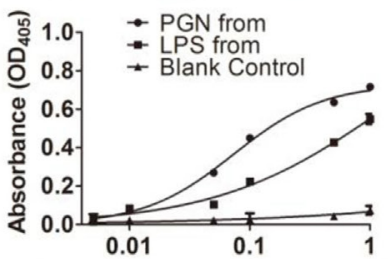

The concentration of protein $(\mu \mathrm{M})$ Anti-CC-CL

D

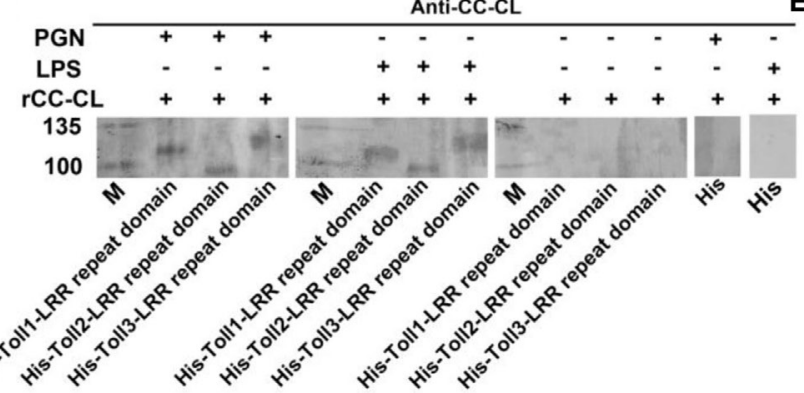

C2

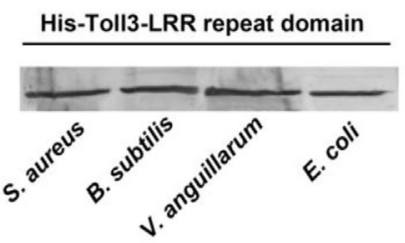

C3

\section{His-Toll3 repeat LRR domain}

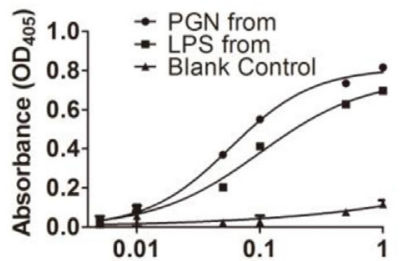

The concentration of protein $(\mu \mathrm{M})$

E $\mathrm{kDa}$

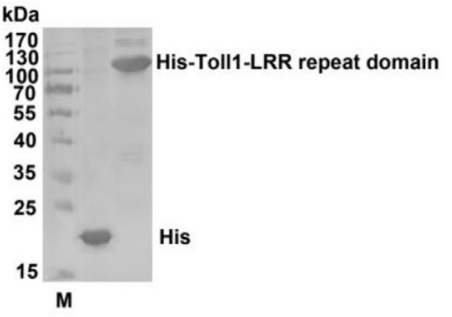

FIGURE 4 | Recombinant Toll1-3 (rToll1-3) bound to bacteria and polysaccharides. (A-C) Domain architectures of Toll1-3. (A1-C1) The leucine-rich repeat (LRR) domains of Toll1 (A1), Toll2 (B1), and Toll3 (C1) were expressed and purified from Escherichia coli. Lane M, protein marker; lane 1, rToll1-3 proteins of E. coli with recombinant vectors before induction with IPTG; lane 2, rToll1-3 proteins of E. coli with recombinant vectors after induced with IPTG; lane 3, purified protein. (A2-C2) Western blotting analyses were performed to analyze the binding activity of rToll1 (A2), rToll2 (B2), and rToll3 (C2) to different bacteria using anti-His antibody. GST or His was used as negative control. (A3-C3) ELISA was performed to detect the binding activities of rToll1 (A3) rToll2 (B3), and rToll3 (C3) to different polysaccharides [PGN and lipopolysaccharide (LPS)]. (D) A far-Western blotting was used to detect if $r$ Toll1, rToll2, and rToll3 could interact with PGN and LPS with anti-CC-CL as first antibody. Purified rTolls were separated by SDS-PAGE and transferred into nitrocellulose membrane, respectively. PGN or LPS was incubated with the membrane containing rToll1, 2, or 3. After washed completely, the recombinant CC-CL, a C-type lectin which can bind to LPS and PGN, but could not interact with Toll1-3, was applied on the membrane. Then anti-CC-CL was incubated with the membrane as the first antibody. (E) His and His-Toll1-LRR domains were purified from E. coli. 


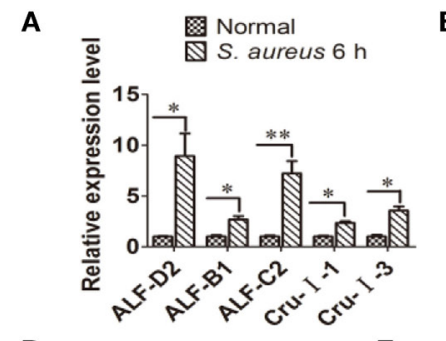

D

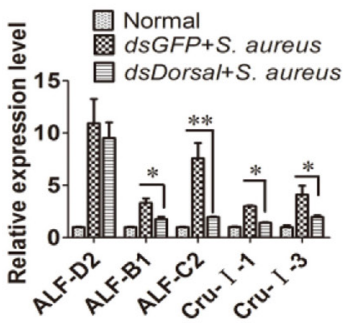

H

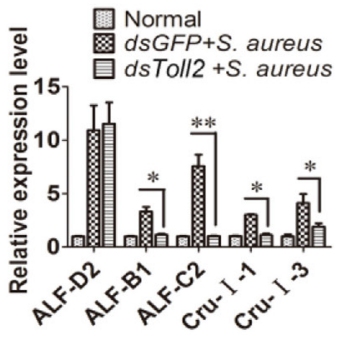

I
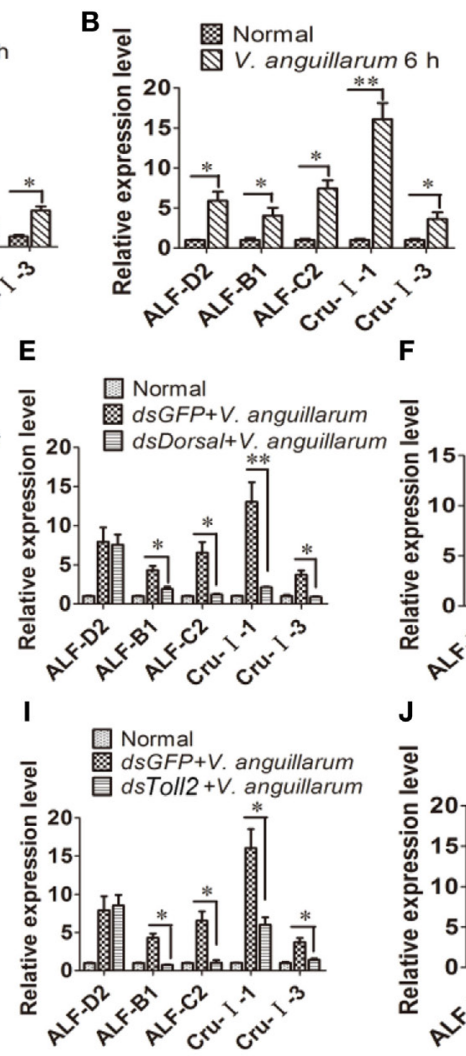

$F$
C
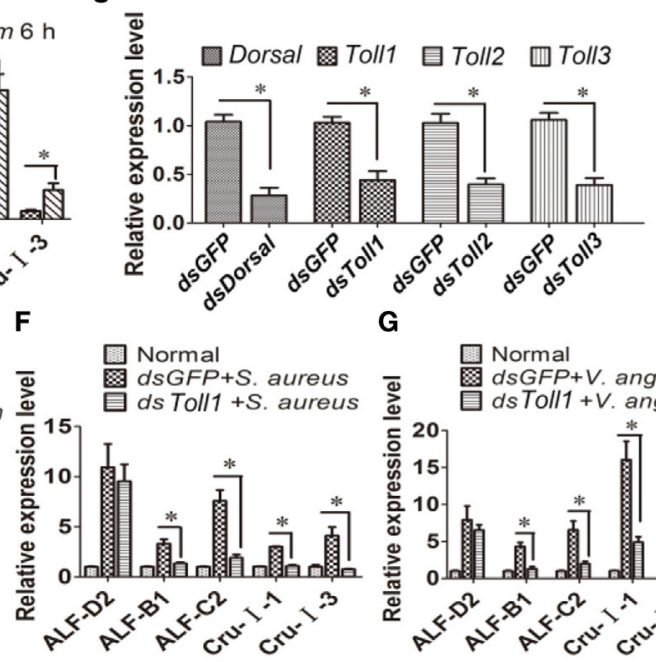

G

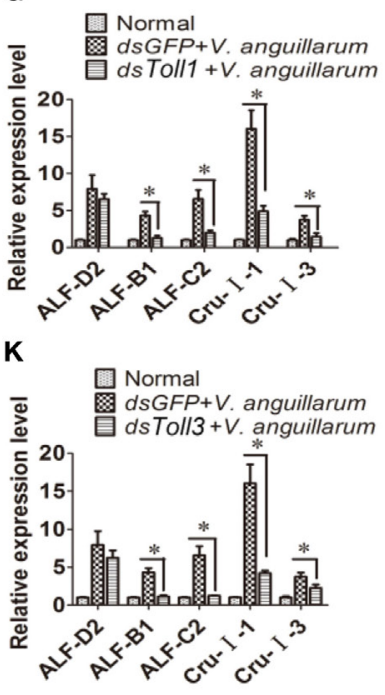

FIGURE $\mathbf{5}$ | Toll pathway regulates the expression of AMPs via the transcription factor Dorsal. (A,B) AMP expression was detected in hemocytes of shrimp after challenge with Staphylococcus aureus (A) or Vibrio anguillarum at $6 \mathrm{~h}$ (B). (C) The RNAi efficiency of Dorsal, Toll1, Toll2, and Toll3 was analyzed by qPCR. (D,E) AMP expression was detected in Dorsal-knockdown shrimp challenged with S. aureus (D) or $V$. anguillarum (E). (F,G) AMP expression was detected in Toll1-knockdown shrimp challenged with S. aureus (F) or V. anguillarum (G). (H,I) AMP expression was detected in Toll2-knockdown shrimp after challenge with S. aureus (H) or V. anguillarum (I). (J,K) AMP expression was detected in Toll3-knockdown shrimp challenged with S. aureus (J) or $V$. anguillarum (K). $\beta$-Actin was used as internal control. Significant differences are indicated with asterisks $\left({ }^{*} p<0.05,{ }^{* *} p<0.01\right)$.

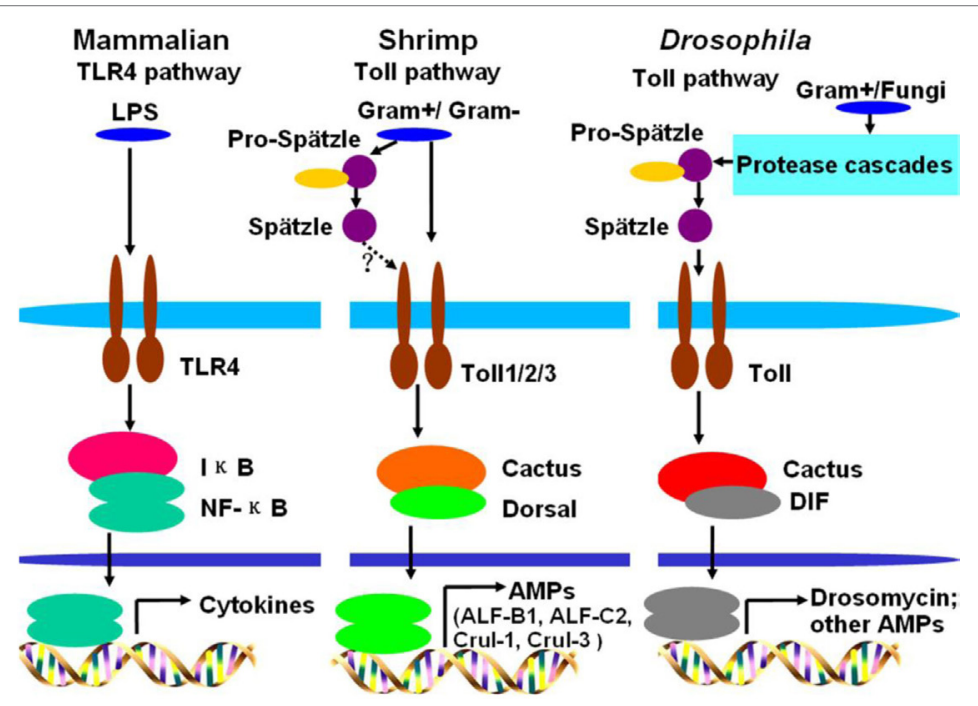

FIGURE 6 | Comparison of Toll pathways among mammals, Drosophila, and shrimp. In mammals, lipopolysaccharide (LPS) activates the Toll-like receptor (TLR) pathway by directly binding to the TLR4 receptor. In Drosophila, $\mathrm{G}^{+}$bacteria or fungi activate the Toll pathway by functional Spätzle binding to Toll. In shrimp, G ${ }^{+}$ bacteria and $\mathrm{G}^{-}$bacteria all can activate the Toll pathway by their pathogen-associated molecular patterns directly binding to Toll receptors. In shrimp, Toll receptors can directly bind to $\mathrm{G}^{+}$and $\mathrm{G}^{-}$bacteria, whether the Spätzles participated in the Toll pathway (like Drosophila) in shrimp still needs further study. 
Toll pathway can direct the expression of drosomycin with antifungal activity in vitro (24). $\mathrm{G}^{-}$bacteria activate the Imd pathway, and diptericin has high anti-Gram-negative bacterial activity. The Toll and Imd pathways were also identified in shrimp (41). Shrimp use a diverse array of AMPs as a part of an important first-line response of the host defense system. AMPs in penaeid shrimp consist of penaeidins (PEN), crustins (Cru), and antilipopolysaccharide factors (ALFs) (52). Both $\mathrm{G}^{+}$and $\mathrm{G}^{-}$bacteria activate the Toll pathway and induce the expression of AMPs, including ALF-B1, ALF-C2, CruI-1, and CruI-3. The Imd pathway in shrimp regulates the expression of ALF-B1, ALF-C2, and ALF-D2 (53). Thus, the pathogens for Toll pathway activation are different between shrimp and Drosophila. Most of the AMPs are regulated by the two pathways, although the responses do not match with the distinct inducers in shrimp.

A comparison of the Toll pathways among mammals, Drosophila, and shrimp is shown in Figure 6. Toll pathway activation in shrimp is similar to the activation of the TLR pathway in

\section{REFERENCES}

1. Kawai T, Akira S. Toll-like receptors and their crosstalk with other innate receptors in infection and immunity. Immunity (2011) 34(5):637-50. doi:10.1016/j.immuni.2011.05.006

2. O'Neill LA, Bowie AG. The family of five: TIR-domain-containing adaptors in toll-like receptor signalling. Nat Rev Immunol (2007) 7(5):353-64. doi:10.1038/nri2079

3. Akira S, Hemmi H. Recognition of pathogen-associated molecular patterns by TLR family. Immunol Lett (2003) 85(2):85-95. doi:10.1016/ S0165-2478(02)00228-6

4. Kasamatsu J, Oshiumi H, Matsumoto M, Kasahara M, Seya T. Phylogenetic and expression analysis of lamprey toll-like receptors. Dev Comp Immunol (2010) 34(8):855-65. doi:10.1016/j.dci.2010.03.004

5. Ligoxygakis P, Bulet P, Reichhart JM. Critical evaluation of the role of the toll-like receptor 18-wheeler in the host defense of Drosophila. EMBO Rep (2002) 3(7):666-73. doi:10.1093/embo-reports/kvf130

6. Bilak H, Tauszig-Delamasure S, Imler JL. Toll and toll-like receptors in Drosophila. Biochem Soc Trans (2003) 31(Pt 3):648-51. doi:10.1042/ bst0310648

7. Ooi JY, Yagi Y, Hu X, Ip YT. The Drosophila toll-9 activates a constitutive antimicrobial defense. EMBO Rep (2002) 3(1):82-7. doi:10.1093/embo-reports/ kvf004

8. Yagi Y, Nishida Y, Ip YT. Functional analysis of toll-related genes in Drosophila. Dev GrowthDiffer (2010) 52(9):771-83.doi:10.1111/j.1440-169X.2010.01213.x

9. Gobert V, Gottar M, Matskevich AA, Rutschmann S, Royet J, Belvin M, et al. Dual activation of the Drosophila toll pathway by two pattern recognition receptors. Science (2003) 302(5653):2126-30. doi:10.1126/science.1085432

10. Leulier F, Parquet C, Pili-Floury S, Ryu JH, Caroff M, Lee WJ, et al. The Drosophila immune system detects bacteria through specific peptidoglycan recognition. Nat Immunol (2003) 4(5):478-84. doi:10.1038/ni922

11. Ligoxygakis P, Pelte N, Hoffmann JA, Reichhart JM. Activation of Drosophila toll during fungal infection by a blood serine protease. Science (2002) 297(5578):114-6. doi:10.1126/science.1072391

12. Lemaitre B, Meister M, Govind S, Georgel P, Steward R, Reichhart JM, et al. Functional analysis and regulation of nuclear import of dorsal during the immune response in Drosophila. EMBO J (1995) 14(3):536-45.

13. Lemaitre B, Nicolas E, Michaut L, Reichhart JM, Hoffmann JA. The dorsoventral regulatory gene cassette spatzle/Toll/cactus controls the potent antifungal response in Drosophila adults. Cell (1996) 86(6):973-83. doi:10.1016/ S0092-8674(00)80172-5

14. Levashina EA, Langley E, Green C, Gubb D, Ashburner M, Hoffmann JA, et al. Constitutive activation of toll-mediated antifungal defense in serpin-deficient Drosophila. Science (1999) 285(5435):1917-9. doi:10.1126/ science.285.5435.1917 mammals, because they all directly bind to PAMPs. In Drosophila, $\mathrm{G}^{+}$bacteria and fungi can activate the Toll pathway via Spätzle binding to the Toll receptor (17). In shrimp, both $\mathrm{G}^{+}$bacteria and $\mathrm{G}^{-}$bacteria can activate the Toll pathway by directly bind to Toll receptors. The activated Toll pathway directs different AMP expression.

\section{AUTHOR CONTRIBUTIONS}

Conceived and designed the experiments: J-XW, J-JS, and X-FZ. Performed the experiments: J-JS, SX, Z-HH, and X-ZS. Analyzed the data and wrote the paper: J-JS and J-XW.

\section{ACKNOWLEDGMENTS}

This work was finically supported by the National Natural Science Foundation of China (Grant Nos. 31630084, 31130056, and 31472303).

15. Horng T, Medzhitov R. Drosophila MyD88 is an adapter in the toll signaling pathway. Proc Natl Acad Sci U S A (2001) 98(22):12654-8. doi:10.1073/ pnas. 231471798

16. Lemaitre B, Hoffmann J. The host defense of Drosophila melanogaster. Annu Rev Immunol (2007) 25:697-743. doi:10.1146/annurev.immunol.25.022106. 141615

17. Valanne S, Wang JH, Ramet M. The Drosophila toll signaling pathway J Immunol (2011) 186(2):649-56. doi:10.4049/jimmunol.1002302

18. Ip YT, Reach M, Engstrom Y, Kadalayil L, Cai H, Gonzalez-Crespo S, et al. Dif, a dorsal-related gene that mediates an immune response in Drosophila. Cell (1993) 75(4):753-63. doi:10.1016/0092-8674(93)90495-C

19. Nicolas E, Reichhart JM, Hoffmann JA, Lemaitre B. In vivo regulation of the IkappaB homologue cactus during the immune response of Drosophila. J Biol Chem (1998) 273(17):10463-9. doi:10.1074/jbc.273.17.10463

20. Tauszig-Delamasure S, Bilak H, Capovilla M, Hoffmann JA, Imler JL. Drosophila MyD88 is required for the response to fungal and Gram-positive bacterial infections. Nat Immunol (2002) 3(1):91-7. doi:10.1038/ni747

21. Hoffmann JA. The immune response of Drosophila. Nature (2003) 426(6962):33-8. doi:10.1038/nature02021

22. Imler JL, Bulet P. Antimicrobial peptides in Drosophila: structures, activities and gene regulation. Chem Immunol Allergy (2005) 86:1-21. doi:10.1159/000086648

23. Shen B, Liu H, Skolnik EY, Manley JL. Physical and functional interactions between Drosophila TRAF2 and Pelle kinase contribute to dorsal activation. Proc Natl Acad Sci U S A (2001) 98(15):8596-601. doi:10.1073/pnas.141235698

24. Fehlbaum P, Bulet P, Michaut L, Lagueux M, Broekaert WF, Hetru C, et al. Insect immunity. Septic injury of Drosophila induces the synthesis of a potent antifungal peptide with sequence homology to plant antifungal peptides. J Biol Chem (1994) 269(52):33159-63.

25. Levashina EA, Ohresser S, Bulet P, Reichhart JM, Hetru C, Hoffmann JA. Metchnikowin, a novel immune-inducible proline-rich peptide from Drosophila with antibacterial and antifungal properties. Eur J Biochem (1995) 233(2):694700. doi:10.1111/j.1432-1033.1995.694_2.x

26. Hultmark D. Drosophila immunity: paths and patterns. Curr Opin Immunol (2003) 15(1):12-9. doi:10.1016/S0952-7915(02)00005-5

27. Nakamoto M, Moy RH, Xu J, Bambina S, Yasunaga A, Shelly SS, et al. Virus recognition by toll-7 activates antiviral autophagy in Drosophila. Immunity (2012) 36(4):658-67. doi:10.1016/j.immuni.2012.03.003

28. Hou F, He S, Liu Y, Zhu X, Sun C, Liu X. RNAi knock-down of shrimp Litopenaeus vannamei toll gene and immune deficiency gene reveals their difference in regulating antimicrobial peptides transcription. Dev Comp Immunol (2014) 44(2):255-60. doi:10.1016/j.dci.2014.01.004

29. Wang PH, Liang JP, Gu ZH, Wan DH, Weng SP, Yu XQ, et al. Molecular cloning, characterization and expression analysis of two novel tolls (LvToll2 and LvToll3) and three putative Spatzle-like Toll ligands (LvSpz1-3) from 
Litopenaeus vannamei.Dev Comp Immunol (2012) 36(2):359-71. doi:10.1016/j. dci.2011.07.007

30. Yang C, Zhang J, Li F, Ma H, Zhang Q, Jose Priya TA, et al. A toll receptor from Chinese shrimp Fenneropenaeus chinensis is responsive to Vibrio anguillarum infection. Fish Shellfish Immunol (2008) 24(5):564-74. doi:10.1016/j. fsi.2007.12.012

31. Arts JA, Cornelissen FH, Cijsouw T, Hermsen T, Savelkoul HF, Stet RJ. Molecular cloning and expression of a toll receptor in the giant tiger shrimp, Penaeus monodon. Fish Shellfish Immunol (2007) 23(3):504-13. doi:10.1016/j. fsi.2006.08.018

32. Deepika A, Sreedharan K, Paria A, Makesh M, Rajendran KV. Toll-pathway in tiger shrimp (Penaeus monodon) responds to white spot syndrome virus infection: evidence through molecular characterisation and expression profiles of MyD88, TRAF6 and TLR genes. Fish Shellfish Immunol (2014) 41(2):441-54. doi:10.1016/j.fsi.2014.09.026

33. Mekata T, Kono T, Yoshida T, Sakai M, Itami T. Identification of cDNA encoding toll receptor, MjToll gene from kuruma shrimp, Marsupenaeus japonicus. Fish Shellfish Immunol (2008) 24(1):122-33. doi:10.1016/j.fsi.2007.10.006

34. Lan JF, Zhao LJ, Wei S, Wang Y, Lin L, Li XC. PcToll2 positively regulates the expression of antimicrobial peptides by promoting PcATF4 translocation into the nucleus. Fish Shellfish Immunol (2016) 58:59-66. doi:10.1016/j. fsi.2016.09.007

35. Wang Z, Chen YH, Dai YJ, Tan JM, Huang Y, Lan JF, et al. A novel vertebrates toll-like receptor counterpart regulating the anti-microbial peptides expression in the freshwater crayfish, Procambarus clarkii. Fish Shellfish Immunol (2015) 43(1):219-29. doi:10.1016/j.fsi.2014.12.038

36. Huang XD, Yin ZX, Jia XT, Liang JP, Ai HS, Yang LS, et al. Identification and functional study of a shrimp dorsal homologue. Dev Comp Immunol (2010) 34(2):107-13. doi:10.1016/j.dci.2009.08.009

37. Li F, Wang D, Li S, Yan H, Zhang J, Wang B, et al. A dorsal homolog (FcDorsal) in the Chinese shrimp Fenneropenaeus chinensis is responsive to both bacteria and WSSV challenge. Dev Comp Immunol (2010) 34(8):874-83. doi:10.1016/j. dci.2010.03.008

38. Sun JJ, Lan JF, Shi XZ, Yang MC, Niu GJ, Ding D, et al. beta-Arrestins negatively regulate the toll pathway in shrimp by preventing dorsal translocation and inhibiting dorsal transcriptional activity. J Biol Chem (2016) 291(14):7488-504. doi:10.1074/jbc.M115.698134

39. Sun JJ, Lan JF, Shi XZ, Yang MC, Yang HT, Zhao XF, et al. A fibrinogen-related protein (FREP) is involved in the antibacterial immunity of Marsupenaeus japonicus. Fish Shellfish Immunol (2014) 39(2):296-304. doi:10.1016/j. fsi.2014.05.005

40. Wang S, Liu N, Chen AJ, Zhao XF, Wang JX. TRBP homolog interacts with eukaryotic initiation factor 6 (eIF6) in Fenneropenaeus chinensis. J Immunol (2009) 182(9):5250-8. doi:10.4049/jimmunol.0802970

41. Li F, Xiang J.Signaling pathways regulating innate immune responses in shrimp. Fish Shellfish Immunol (2013) 34(4):973-80. doi:10.1016/j. fsi.2012.08.023
42. Belvin MP, Anderson KV. A conserved signaling pathway: the Drosophila toll-dorsal pathway. Annu Rev Cell Dev Biol (1996) 12:393-416. doi:10.1146/ annurev.cellbio.12.1.393

43. Pasare C, Medzhitov R. Toll-like receptors: linking innate and adaptive immunity. Adv Exp Med Biol (2005) 560:11-8. doi:10.1007/0-387-24180-9_2

44. Akira S, Takeda K. Toll-like receptor signalling. Nat Rev Immunol (2004) 4(7):499-511. doi:10.1038/nri1391

45. Ren Q, Lan JF, Zhong X, Song XJ, Ma F, Hui KM, et al. A novel toll like receptor with two TIR domains (HcToll-2) is involved in regulation of antimicrobial peptide gene expression of Hyriopsis cumingii. Dev Comp Immunol (2014) 45(1):198-208. doi:10.1016/j.dci.2014.02.020

46. Wang W, Zhang T, Wang L, Xu J, Li M, Zhang A, et al. A new non-phagocytic TLR6 with broad recognition ligands from Pacific oyster Crassostrea gigas. Dev Comp Immunol (2016) 65:182-90. doi:10.1016/j.dci.2016.07.010

47. Shi XZ, Zhang RR, Jia YP, Zhao XF, Yu XQ, Wang JX. Identification and molecular characterization of a Spatzle-like protein from Chinese shrimp (Fenneropenaeus chinensis). Fish Shellfish Immunol (2009) 27(5):610-7. doi:10.1016/j.fsi.2009.07.005

48. Yuan K, Yuan FH, Weng SP, He JG, Chen YH. Identification and functional characterization of a novel Spatzle gene in Litopenaeus vannamei. Dev Comp Immunol (2016) 68:46-57. doi:10.1016/j.dci.2016.11.016

49. Ren Q, Huang X, Cui Y, Sun J, Wang W, Zhang X. Two white spot syndrome virus microRNAs target the dorsal gene to promote virus infection in Marsupenaeus japonicus shrimp. J Virol (2017) 91(8):e2261-2216. doi:10.1128/JVI.02261-16

50. Lindsay SA, Wasserman SA. Conventional and non-conventional Drosophila toll signaling. Dev Comp Immunol (2014) 42(1):16-24. doi:10.1016/j. dci.2013.04.011

51. Myllymaki H, Valanne S, Ramet M. The Drosophila imd signaling pathway. J Immunol (2014) 192(8):3455-62. doi:10.4049/jimmunol.1303309

52. Tassanakajon A, Amparyup P, Somboonwiwat K, Supungul P. Cationic antimicrobial peptides in penaeid shrimp. Mar Biotechnol (NY) (2011) 13(4):639-57. doi:10.1007/s10126-011-9381-8

53. Liu N, Wang XW, Sun JJ, Wang L, Zhang HW, Zhao XF, et al. Akirin interacts with Bap60 and 14-3-3 proteins to regulate the expression of antimicrobial peptides in the kuruma shrimp (Marsupenaeus japonicus). Dev Comp Immunol (2016) 55:80-9. doi:10.1016/j.dci.2015.10.015

Conflict of Interest Statement: The authors declare that the research was conducted in the absence of any commercial or financial relationships that could be construed as a potential conflict of interest.

Copyright $\odot 2017$ Sun, Xu, He, Shi, Zhao and Wang. This is an open-access article distributed under the terms of the Creative Commons Attribution License (CC BY). The use, distribution or reproduction in other forums is permitted, provided the original author(s) or licensor are credited and that the original publication in this journal is cited, in accordance with accepted academic practice. No use, distribution or reproduction is permitted which does not comply with these terms. 